\title{
GAMBARAN KESEJAHTERAAN SPIRITUAL USHER DEWASA MADYA DI GEREJA X JAKARTA
}

\author{
Graciella Faren $^{1}$, Raja Oloan Tumanggor ${ }^{2}$ \\ ${ }^{1}$ Fakultas Psikologi, Universitas Tarumanagara Jakarta \\ Email: graciella.705160157@stu.untar.ac.id \\ ${ }^{2}$ Fakultas Psikologi, Universitas Tarumanagara Jakarta \\ Email: rajat@fpsi.untar.ac.id
}

\begin{abstract}
Well-being is something that most people look for. Not only about material, well-being is essentially an achievement of harmony in life from physical, intellectual, social, mental, and also spiritual aspects. Likewise, spirituality becomes one of the supports of individuals to carry out life. Spiritual well-being is important in the lives of middle-aged individuals who have experienced many changes in their lives. These changes have a certain impact on the lives of middle-aged individuals, where middle-aged individuals will evaluate themselves more and live a better quality. This study aims to determine the description of the spiritual well-being of church servants "Church X" in Jakarta. Spiritual well-being is not only focused on the person and God, but other dimensions are related to one another. The research method used is a mixed method that combines questionnaires and interviews. The subjects of this study are the church servants in "Church X" Jakarta, amounting to 33 servants who distributed questionnaires and 3 servants to be interviewed. From the results of the study, it can be concluded that the picture of spiritual well-being of churchservants in Church $X$ is said to be high and has positive well-being from every dimension, personal, communal, environmental and, transcendental.
\end{abstract}

Keywords: Spiritual well-being, church servants, middle-aged

\begin{abstract}
ABSTRAK
Kesejahteraan adalah sesuatu yang dicari oleh kebanyakan orang. Tidak hanya materi, kesejahteraan pada hakikatnya merupakan pencapaian keharmonisan dalam hidup baik dari aspek fisik, intelektual, sosial, mental maupun spiritual. Demikian pula spiritualitas menjadi salah satu penunjang individu dalam menjalani kehidupan. Kesejahteraan spiritual penting dalam kehidupan individu paruh baya yang telah mengalami banyak perubahan dalam hidup mereka. Perubahan ini memiliki dampak tertentu pada kehidupan individu paruh baya, di mana individu paruh baya akan lebih mengevaluasi diri dan menjalani kualitas yang lebih baik. Penelitian ini bertujuan untuk mengetahui gambaran kesejahteraan spiritual pelayan gereja di Jakarta. Kesejahteraan spiritual tidak hanya terfokus pada pribadi dan Tuhan, tetapi dimensi lain terkait satu dengan yang lainnya. Metode penelitian yang digunakan adalah metode campuran yang menggabungkan kuesioner dan wawancara. Subjek penelitian ini adalah abdi gereja di "Gereja X" Jakarta yang berjumlah 33 orang dengan menyebarkan kuesioner dan 3 orang untuk diwawancarai. Dari hasil penelitian dapat disimpulkan bahwa gambaran kesejahteraan spiritual hamba-hamba Gereja di Gereja X dikatakan tinggi dan memiliki kesejahteraan yang positif dari setiap dimensi baik personal, komunal, lingkungan dan transendental.
\end{abstract}

Kata Kunci: Kesejahteraan spiritual, paruh baya, pelayan gereja

\section{PENDAHULUAN}

\section{Latar Belakang}

Kesejahteraan pada hakikatnya merupakan keadaan individu mampu mencapai keselarasan dalam hidup dari seluruh aspek yakni fisik, intelektual, sosial, mental dan juga spiritual. Sejalan dengan pernyataan Sodiq (2016), kesejahteraan merupakan harapan individu dalam hidupnya yang berupa kesejahteraan materi maupun kesejahteraan spiritual. Dalam Undang-Undang Nomor 11 tahun 2009 mengenai kesejahteraan sosial, dijelaskan bahwa kesejahteraan merupakan kondisi terpenuhinya kebutuhan material, spiritual dan sosial warga negara agar dapat hidup layak dan mampu mengembangkan diri, sehingga dapat melaksanakan fungsi sosialnya. Banyak pemikiran mengenai kesejahteraan hanya berpatok pada terpenuhinya hal materi saja tanpa melihat aspek spiritual. Hal tersebut dapat dilihat dalam indikator kesejahteraan Badan Pusat Statistik (2018), 
bahwa untuk mengukur kondisi kesejahteraan dilihat dari keadaan kependudukan, kesehatan, pendidikan, fertilitas atau keturunan, keadaan rumah, akses teknologi dan informasi, serta pengeluaran. Kesejahteraan spiritual seperti dianggap sebelah mata sehingga perhatiannya lebih sedikit.

Spiritualitas menjadi salah satu kemampuan yang dapat dilakukan, karena membuat manusia kuat dalam menghadapi masalah dan menjadi sumber pencarian makna hidup (Shirkavand et al., 2018). Selain itu, spiritualitas juga merupakan dimensi dari kesehatan dan kesejahteraan individu. Dimensi tersebut yaitu dimensi vertikal, yang di dalamnya terdapat hubungan dengan Tuhan, dan dimensi horizontal, yang di dalamnya terdapat tujuan, makna dan kepuasan hidup (Fisher, 2011). Spiritualitas dapat membantu individu dalam mengatasi masalah hidup, menghadapi tekanan, dan masalah kesehatan. Kepercayaan spiritual menjadi sangat penting ketika individu dihadapi dengan stres, penyakit, kehilangan dan rasa duka. Keyakinan dan pengalaman dalam spiritual dapat mengubah hidup mereka, memberi kekuatan, serta memengaruhi kesejahteraannya (Saleem \& Khan, 2015). Oleh karena itu, kesejahteraan spiritual juga disebut sebagai hubungan kehidupan batin individu dengan kehidupan di sekitarnya, serta diyakini sebagai sumber coping penyembuhan dan pemulihan diri (Shafi et al., 2016).

Kesejahteraan spiritual memiliki koneksi antara individu dengan dirinya sendiri, orang lain, alam, dan Tuhan. Koneksi ini dijelaskan oleh Fisher (2010) yang mengelompokkannya menjadi empat dimensi, yaitu: a) dimensi pribadi, yang berkaitan dengan pribadi individu; b) dimensi komunal, yang berkaitan dengan interpersonal; c) dimensi lingkungan, yang berkaitan dengan lingkungan secara natural; dan d) dimensi transendental, yang berkaitan dengan hubungan dengan Tuhan. Pernyataan tersebut sejalan dengan Saleem dan Khan (2015) yang mengatakan bahwa spiritualitas dipengaruhi oleh komunitas di mana individu menjadi bagian, serta akan lebih baik jika individu terlibat secara positif dengan orang lain, diri sendiri dan lingkungan.

Beberapa hasil penelitian yang dilakukan di lingkup gereja juga dilakukan oleh Musa et al. (2015) mengenai kesejahteraan spiritual. Penelitian tersebut menggunakan metode kuantitatif terhadap 340 individu Yordania-Arab Kristiani yang berusia 18 tahun ke atas. Hasil penelitian menunjukan bahwa kesejahteraan spiritual memiliki hasil statistik yang positif dan secara positif terkait dengan penilaian diri. Penelitian lain yang juga dilakukan di lingkup gereja dibuat oleh Wilkinson et al. (2018). Mereka meneliti mengenai kesejahteraan spiritual pada 468 individu Kristiani di 18 gereja di Irlandia. Hasil studi mereka menunjukan bahwa frekuensi doa secara pribadi merupakan prediktor yang kuat dalam kesejahteraan spiritual dan hal ini membuktikan bahwa doa pribadi merupakan kunci dalam pembentukan spiritualitas yang berkualitas pada individu.

Berdasarkan penelitian-penelitian terdahulu yang menggunakan subjek penelitian mahasiswa atau perkembangan dewasa muda, peneliti tertarik untuk melakukan penelitian kesejahteraan spiritual dengan menggunakan subjek dewasa madya. Dewasa madya merupakan masa di mana individu melewati perubahan-perubahan yang terjadi dalam hidupnya seperti perubahan fisik karena menua, pensiun dari pekerjaan, naik-turunnya usaha, perasaan kesepian yang disebabkan oleh pasangan hidup kemudian meninggal, dan/atau anak-anak yang sudah dewasa kemudian menikah. Perubahan-perubahan dalam masa ini membuat individu dewasa madya dapat menyesuaikan diri dengan perannya yang berubah, diikuti dengan perubahan fisik yang membuat individu cenderung memiliki masalah kesehatan (Papalia \& Old's, dalam Muzakkiyah \& Suharman, 2015). Perubahan-perubahan yang dialami individu dewasa madya menjadikan kesejahteraan spiritual sebagai faktor kuat untuk menjalani periode perkembangan ini, sehingga walaupun dihadapi dengan stres dan permasalahan, kesejahteraan spiritual dapat menjadi penopangnya. Hal serupa 
dikatakan oleh Lee dan Waters (dalam Bonet, 2009) bahwa kesejahteraan spiritual dapat menjadi penopang bagi individu ketika dihadapkan dengan stres.

Kesejahteraan spiritual menjadi sebuah pokok penting dalam kehidupan individu dewasa madya. Selain dihadapkan dengan perubahan-perubahan psikososialnya, individu dewasa madya ada dalam posisi lebih sadar akan usia dan hari tua, sehingga individu dewasa madya akan mempersiapkan diri untuk menjadi pribadi yang lebih baik. Pada masa ini, individu dewasa madya juga dianggap sudah memiliki banyak pengalaman dalam bekerja dan dihadapkan pada keadaan memasuki masa pensiun (Rohim, 2016). Di usia yang tidak lagi muda, individu dewasa madya mulai menyadari akan keterbatasannya dan kehidupannya kelak yang mulai mendekati dengan kematian, sehingga hal ini menjadi sebuah evaluasi bagi individu dewasa madya (Frankl dalam Rohim, 2016). Dalam mengevaluasi kehidupan, individu dewasa madya mulai mengembangkan spiritualitas dalam dirinya untuk lebih memperkuat makna dalam hidupnya (Kokko dalam Krok, 2015). Sesuai pula dengan yang dikatakan Jung (dalam Yanaputri, 2016) bahwa individu dewasa madya akan lebih menelusuri aspek spiritual dari yang sebelumnya mengurusi hal yang berfokus pada pekerjaan dan keluarga. Pada masa ini individu dewasa madya akan lebih memperbanyak kegiatannya untuk beribadah, mengikuti kegiatan keagamaan, juga lebih banyak menjaga hubungan bermasyarakat.

Kegiatan kerohanian ini seperti berdoa, datang ke gereja setiap minggu dan membaca kitab suci. Namun, kegiatan kerohanian tersebut akan lebih efektif jika ada kegiatan nyata seperti membantu saudara seiman tanpa pamrih (Kosalina, 2018). Kegiatan nyata itu disebut sebagai pelayanan. Menurut Powers et al. (dalam Kosalina, 2018) pelayanan seperti motif yang didasarkan nilai spiritual untuk menolong orang lain, akan menghasilkan perasaan yang positif. Perkumpulan atau komunitas spiritual seperti pelayanan di gereja dapat menjadi wadah dan kesempatan untuk individu dewasa madya berinteraksi dan memperluas hubungan sosial. Komunitas pelayan gereja dinilai dapat membangun rasa kebersamaan, para anggota merasa dicintai, dihargai dan diperhatikan (Kosalina, 2018). Dengan demikian, keterlibatan individu dalam sebuah pelayanan gereja dapat meningkatkan kesejahteraan sehingga memunculkan perasaan bermakna pada dirinya.

Pelayanan dalam teologi Kristen juga memiliki arti panggilan. Panggilan ini diyakini sebagai panggilan Tuhan kepada individu, yang berkaitan dengan komitmen dalam melibatkan seluruh hidupnya untuk melayani Tuhan (Mutak, 2014). Individu yang memutuskan untuk menjadi pelayan Tuhan di gereja harus memiliki kehidupan spiritual yang selalu bertumbuh. Pelayan Tuhan secara umum seseorang yang melakukan pekerjaan gerejawi seperti berkhotbah, memimpin pujian, mengajar, tergabung dalam organisasi kegiatan gereja, bermain alat musik dan aktivitas gereja lainnya yang ada di lingkungan gereja atau disebut juga kegiatan rohani (Sabdono dalam Sumiwi, 2019).

Dalam iman Kristiani, pelayan Tuhan merupakan hamba Tuhan yang sadar bahwa hidupnya milik Kristus. Hal ini dikarenakan Kristus telah menebus dosa dan hidupnya sehingga memiliki komitmen untuk melayani dalam hidupnya dan memiliki ketaatan dan kerendahan hati (Sumiwi, 2019). Kerendahan hati dimiliki oleh pelayan Tuhan agar mereka tidak memiliki rasa ingin dihormati atau kesombongan. Pelayan Tuhan harus selalu memperhatikan orang lain, dapat menjaga rahasia, memiliki kesetiaan dan tanggung jawab pada tugasnya dan tentunya pada gereja (Sumiwi, 2019). Dalam pelayanan di gereja, tentunya melibatkan setiap individu Kristen yang berjemaat untuk melakukan pelayanan (Sari, 2016). Prasetya et al. (dalam Sandi, 2017) menjelaskan bahwa terdapat beberapa jenis pelayanan yang ada dalam gereja dan pelayanan 
tersebut membutuhkan seseorang dengan tenaganya agar pelayanan tersebut dapat dilaksanakan. Pelayanan dalam gereja sejauh ini terdiri dari worship leader, usher (penerima jemaat), pemusik, singer, paduan suara, pendoa dan pelayanan lainnya.

Usher dalam pelayanan gereja yang berarti penerima jemaat merupakan wajah dari sebuah gereja. Hal ini karena usher memiliki tugas untuk menyambut jemaat, mengarahkan jemaat dan mempersiapkan tempat ibadah agar jemaat dapat mengikuti ibadah serta merasakan hadirat Tuhan (Eksafandi, 2019). Istilah usher tidak disebutkan dalam Alkitab, namun pelayanan usher sudah sejak lama ada di dalam Perjanjian Lama di mana kaum Lewi bertugas untuk menjaga pintu-pintu Bait Suci. Dalam Alkitab, Yehezkiel 44:11 "Di dalam tempat kudus-Ku merekalah yang mendapat tugas penjagaan di pintu-pintu gerbang Bait Suci dan tugas pelayanan di dalam Bait Suci; merekalah yang menyembelih korban bakaran dan korban sembelihan bagi bangsa itu dan bertugas bagi bangsa itu untuk melayaninya". Di banyak gereja, usher atau penyambut jemaat masih menerapkan kebiasaan baik dari kaum Lewi yang ditunjukan ketika jemaat masuk ke dalam gereja, jemaat disambut dengan senyum yang ramah dan mengajak jemaat untuk bersama menikmati kehangatan gereja (Rishmawy, 2016). Hal tersebut merupakan salah satu kriteria yang harus dimiliki oleh pelayan gereja usher.

Berdasarkan hasil penelitian sebelumnya terkait kesejahteraan spiritual, peneliti tertarik untuk melakukan penelitian mengenai kesejahteraan spiritual. subjek yang digunakan dalam penelitian ini, yaitu individu dewasa madya, karena dewasa madya mengalami perkembangan dalam bidang spiritual. Alasan lain yang membuat peneliti ingin melakukan penelitian ini, karena dewasa madya mengalami perubahan pada aspek fisik, kognitif, karir dan pekerjaan, serta aspek spiritualitasnya (Santrock, 2011). Selain itu, individu dewasa madya juga mulai lebih banyak melakukan kegiatan spiritual sebagai bentuk mendekatkan diri kepada Tuhan (Rishmaway, 2016). Melalui penelitian ini, peneliti berharap dapat memahami bagaimana gambaran kesejahteraan spiritual dari masingmasing individu dewasa madya yang bergabung dalam komunitas pelayanan sebagai usher.

\section{Rumusan Masalah}

Rumusan masalah pada penelitian ini adalah bagaimana gambaran kesejahteraan spiritual dewasa madya yang menjadi pelayan di gereja?

\section{METODE PENELITIAN}

\section{Subjek penelitian}

Subjek dalam penelitian ini adalah: a) tiga orang dewasa madya atau dewasa tengah yang berada di rentang usia 40 - 65 tahun; b) beragama Kristen; c) menjadi anggota pelayan usher gereja X; dan d) berdomisili di daerah Jakarta, Bogor, Depok, Tangerang dan Bekasi (JABODETABEK).

\section{Jenis penelitian}

Penelitian ini menggunakan jenis penelitian mix method yang bersifat menjelaskan (explanatory). Penelitian ini berfokus pada pengumpulan dan analisis data yang menggabungkan antara data kuantitatif dan data kualitatif. Data kuantitatif digunakan untuk menganalisa dan membuktikan data melalui bentuk angka serta mendukung data gambaran tingkat kesejahteraan spiritual. Data kualitatif digunakan untuk mengetahui lebih dalam bagaimana gambaran kesejahteraan spiritual pada dewasa madya berdasarkan pada nilai tertinggi dan terendah dari hasil data kuantitatif dengan mengambil tiga dewasa madya sebagai sampel. 


\section{Instrumen penelitian}

Alat ukur yang digunakan dalam penelitian ini adalah alat ukur Spiritual Health and Life Orientation (SHALOM) yang dibuat oleh John Wayne Fisher (2010) memiliki 20 item yang terbagi menjadi 4 dimensi, yakni dimensi personal, dimensi communal, dimensi environmental, dan dimensi transcendental dengan masing-masing dimensi terdiri dari 5 item. Item yang ada disusun menggunakan skala Likert dengan 5 pilihan bagi subjek dari skor $1-5$ dengan interpretasi skor $1=$ sangat rendah, skor $2=$ rendah, skor $3=$ sedang, skor $4=$ tinggi, dan skor $5=$ sangat tinggi.

\section{HASIL DAN PEMBAHASAN Hasil Penelitian}

Tabel 1. Gambaran Kesejahteraan Spiritual

\begin{tabular}{lcccccc}
\hline Dimensi & N & Minimum & Maximum & $\begin{array}{l}\text { Mean } \\
\text { empirik }\end{array}$ & $\begin{array}{l}\text { Mean } \\
\text { hipotetik }\end{array}$ & $\begin{array}{l}\text { Std. } \\
\text { Deviation }\end{array}$ \\
\hline Diri & 33 & 3,40 & 5,00 & 4,4667 & 3,00 & 0,50415 \\
\hline Orang Lain & 33 & 3,60 & 5,00 & 4,4848 & 3,00 & 0,45834 \\
\hline Lingkungan & 33 & 2,60 & 5,00 & 4,1455 & 3,00 & 0,70049 \\
\hline Transenden & 33 & 4,00 & 5,00 & 4,8303 & 3,00 & 0,26982 \\
\hline SHALOM & 33 & 3,70 & 5,00 & 4,4818 & 3,00 & 0,42808 \\
\hline
\end{tabular}

Berdasarkan data yang telah diperoleh, kesejahteraan spiritual memiliki hasil mean empirik sebesar 4,4818. Hasil mean empirik lebih besar daripada mean hipotetik menunjukan bahwa gambaran kesejahteraan spiritual pada di Gereja X dikatakan tinggi. Gambaran dimensi diri atau personal menunjukan bahwa mean empirik sebesar 4,4667. Hal ini menunjukan bahwa gambaran dimensi diri atau personal pada subjek di Gereja X tinggi. Gambaran data pada dimensi orang lain atau communal menunjukan bahwa mean empirik sebesar 4,4848. Hal ini menunjukan bahwa gambaran dimensi orang lain atau communal pada subjek di Gereja X tinggi.

Gambaran data pada dimensi lingkungan atau environmental menunjukan bahwa hasil mean empirik sebesar 4,1455. Hal ini menunjukan bahwa gambaran dimensi lingkungan atau environmental pada subjek di Gereja X tinggi. Gambaran dimensi transenden atau transcendental menunjukan bahwa hasil mean empirik sebesar 4,8303. Hal ini menunjukan bahwa gambaran dimensi lingkungan atau environmental pada subjek di Gereja $\mathrm{X}$ dapat tinggi.

\section{Pembahasan}

Hasil penelitian berdasarkan data kualitatif yang diperoleh, subjek NC, subjek SR dan subjek PN memiliki kedamaian dalam diri dan rasa kepuasan terhadap hidupnya. Hal ini ditunjukkan dengan rasa bersyukur. subjek NC dan subjek PN merasa lebih bermakna dan berkualitas menjalani kehidupan setelah memutuskan dirinya melayani Tuhan dalam pelayanan gereja. Sejalan pula dengan subjek SR yang telah terjun melayani lebih lama dan bertumbuh melayani di Gereja X menjadikan pelayanan sebagai tujuan dari hidupnya. Semua ini sesuai dengan yang dikatakan oleh Mutak (2014) bahwa individu berkomitmen untuk melibatkan seluruh kehidupannya untuk melayani Tuhan di mana komitmen ini dirasa sebagai panggilan. Ketika bergabung menjadi pelayan gereja, semua subjek merasakan kepuasan dan ketenangan dalam diri dan menjalani hidup. Fisher (2016) juga mengatakan dalam penelitiannya bahwa individu yang bergaul dengan Tuhan dapat berhubungan dengan diri sendiri dan orang lain dengan baik. 
Semua subjek merasakan ketenangan dalam hidup, karena menanamkan keyakinan pada diri masing-masing akan penyertaan Tuhan. Oleh sebab itu, semua subjek mampu menjalani kehidupan walaupun masalah dalam hidup menerpa. Khususnya subjek PN juga mengaku bahwa ketika mengenal Tuhan dan memaknai hidupnya, PN mulai untuk mengevaluasi diri dan mengoreksi dirinya menjadi lebih baik. Sejalan dengan pernyataan Kokko (dalam Krok, 2015) bahwa dewasa madya yang mulai memfokuskan dirinya pada spiritualitas atau terjun ke dalam pelayanan, akan mengevaluasi kehidupan dan memperkuat makna hidupnya. Begitu pula yang dikatakan oleh Santrock (2011) mengenai makna hidup di mana individu dewasa madya mulai menyadari akan eksistensinya dan mengevaluasi diri.

Subjek NC, subjek SR dan subjek PN dapat menjalin hubungan sosial dengan baik. Dalam lingkungan gereja, ketiganya selaras bahwa tidak terlalu ingin memiliki hubungan yang begitu lekat dengan rekan pelayanan yang lainnya. Namun, tetap pada hubungan sosial yang sewajarnya dan membangun rasa percaya sewajarnya. Hal ini sesuai dengan penelitian Fisher dan Wong (2013) di mana teman atau rekan pelayanan mungkin dapat berkontribusi pada beberapa aspek kesejahteraan, seperti kesejahteraan sosial atau emosional, namun mereka tidak terbukti secara signifikan dalam kesejahteraan spiritual. subjek NC dan subjek SR sebagai pemimpin dalam pelayanan gereja, membuat NC dan SR lebih banyak berkumpul dengan rekan pelayanan lainnya dan mengikuti banyak pertemuan. Sesuai dengan yang dikatakan oleh Kosalina (2018) di mana perkumpulan gereja dapat membangun rasa kebersamaan satu sama lain, kesempatan untuk berinteraksi dan memperluas hubungan sosial. Semua subjek tetap menunjukkan rasa kepedulian, perhatian dan mengasihi satu sama lain kepada orang lain. Peneliti melihat perbedaan gaya dari masing-masing subjek ketika mengekspresikan rasa kepedulian, perhatian dan mengasihi orang lain. Mulai dari saling menanyakan keadaan satu sama lain, membantu orang lain dan menyenangkan orang lain dengan hal-hal kecil. Sejalan dengan yang dikatakan oleh Kosalina (2018) di mana kegiatan pelayanan di dalamnya ada rasa untuk membantu dan menolong sesama tanpa pamrih. Begitu pula Fisher (2016) mengatakan bahwa kehidupan sosial individu dapat mengekspresikan kasih sayang, pengampuan serta iman dalam kemanusiaan. Ketiga subjek juga belajar untuk mengendalikan diri ketika dihadapkan dengan masalah dengan orang lain, dan mengampuni juga memaafkan.

Saat menjelaskan mengenai lingkungan alam, ketiganya merupakan pribadi yang senang pergi menikmati alam, dan mampu menunjukan kekaguman keindahan alam yang mereka temui. subjek NC, SR dan PN memiliki jawaban yang selaras bahwasannya lingkungan alam yang indah merupakan salah satu karya Tuhan dan ketiganya mensyukuri akan kesempatan yang Tuhan berikan. Di samping itu, subjek NC, SR dan PN juga dapat melakukan dialog dengan alam sebagai bentuk rasa kagum dan syukur kepada Tuhan akan kebaikan-kebaikan yang telah diberikan dan ciptaanNya.

Begitu pula dalam hubungan transenden, ketiga subjek menggambarkan hubungan dengan Tuhan sebagai hubungan yang intim di mana ketiga subjek dapat mengekspresikan perasaannya. subjek NC, SR dan PN terus menjaga hubungan dengan Tuhan. Ketiga subjek bahkan memiliki pengalamannya masing-masing dengan Tuhan ketika sedang berkomunikasi dengan Tuhan. Ketiga subjek dapat menggambarkan Tuhan sebagai sahabat dan juga Bapak, sehingga ketiga subjek merasakan kenyamanan yang luar biasa. Hal ini sesuai yang dikatakan oleh Fisher (2013) bahwa dimensi transendental memiliki nilai yang tinggi dalam kesejahteraan spiritual dan disimpulkan bahwa memiliki hubungan dengan Tuhan terbukti paling penting dalam kesejahteraan spiritual individu. Pada dimensi ini, ketiga subjek memiliki nilai paling tinggi dibandingkan tiga 
dimensi lainnya.

\section{KESIMPULAN DAN SARAN Kesimpulan}

Berdasarkan hasil data kuantitatif yang telah dilakukan, dapat disimpulkan bahwa kesejahteraan spiritual pada pelayan Gereja X di Jakarta dikatakan tinggi. Berdasarkan hasil data kualitatif disimpulkan bahwa pelayan gereja di Gereja X yang memiliki skor kesejahteraan spiritual tinggi, memiliki rasa kepuasaan terhadap dirinya sendiri yang ditunjukkan dengan rasa syukur dan memaknai hidupnya sebagai kebaikan yang Tuhan berikan sehingga pelayanan di Gereja ditunjukkan sebagai tujuan dari hidup dan lebih intim dengan Tuhan. Hubungan pelayan gereja dengan rekan pelayanan yang lainnya terjalin baik. Walaupun gesekan selalu ada, namun tetap menunjukan rasa kasih dan memperbaiki. Begitu pula ketika menemui lingkungan alam yang indah, pelayan gereja ekspresikan dengan rasa takjub sebagai rasa kagum akan ciptaan Tuhan. Pelayan gereja juga mendeskripsikan hubungan dengan Tuhan sebagai hubungan yang intim.

\section{Saran}

Hasil penelitian menunjukan bahwa tidak ada perbedaan yang signifikan dari kedua metode yang digunakan. Hasil dari kesejahteraan spiritual yang tinggi, juga tergambarkan pada setiap dimensidimensi kesejahteraan spiritual yang ada. Oleh karena itu, saran yang dapat diberikan oleh peneliti pada dimensi diri adalah kiranya subjek selalu mempertahankan situasi perbaikan dalam diri seperti evaluasi dan terus memaknai kehidupan yang dijalaninya setiap hari. Pada dimensi komunal, kiranya subjek dapat mempertahankan hal yang sudah baik dalam diri subjek seperti terus mengasihi, berbuat baik pada sesama, dan terus meningkatkan hubungan yang berkualitas dengan sesama. Pada dimensi lingkungan, kiranya masing-masing subjek dapat terus menjaga dan merawat lingkungan alam yang ada di sekitarnya serta selalu mensyukuri akan keindahan alam yang Tuhan ciptakan. Pada dimensi transenden, masing-masing subjek dapat terus membangun dan mempertahankan hubungan yang berkualitas dengan Tuhan pada setiap waktu kehidupan.

\section{Ucapan Terima Kasih (Acknowledgement)}

Peneliti mengucapkan terima kasih kepada Gereja X Jakarta yang telah memberikan izin kepada peneliti untuk melakukan pengambilan data secara langsung. Peneliti juga mengucapkan terima kasih kepada semua partisipan yang telah meluangkan waktunya untuk menjadi partisipan dalam penelitian ini. Ucapan terima kasih juga peneliti ucapkan kepada seluruh pihak yang telah membantu dan mendukung peneliti dalam proses penelitian ini.

\section{REFERENSI}

Badan Pusat Statistik. (2018). Berita resmi statistik. https://jaktimkota.bps.go.id/publication/2018/12/28/6f3464bf5be89f829b7a5472/statisti k- kesejahteraan-rakyat-kota-jakarta-timur-2018.

Bonet, M. (2009). The impact of spiritual well-being and stressful life experiences on traumatic stress [Disertasi, Seton Hall University]. https://scholarship.shu.edu/cgi/viewcontent.cgi?referer=https://scholar.google.com/\&htt psredir $=1 \&$ article $=2603 \&$ context $=$ dissertations

Eksafandi, T. (2019). An overview about usher ministry. GMS Jakarta.

Diakses pada Juli 5, 2020, dari https://jakarta.mawarsharon.com/usher/

Fisher, J. (2010). Development and application of a spiritual well-being questionnaire called SHALOM. Religions, 1(1), 101-121. https://doi.org/10.3390/rel1010105

Fisher, J. (2011). The four domains model: Connecting spirituality, health and well-being. Religions, 2, 17-28. https://doi.org/10.3390/rel2010017 
Fisher, J. (2013). You can't beat relating with god for spiritual well-being: Comparing a generic version with the original spiritual well-being questionnaire called shalom. Religions, 4, 325-335. https://doi.org/10.3390/re14030325

Fisher, J. (2016). Selecting the best version of SHALOM to assess spiritual well-being. Religions, 7(45). https://doi.org/10.3390/rel7050045

Fisher, J. W. \& Wong, P. H. (2013). Comparing levels of spiritual well-being and support among pre-service teachers in Hong Kong and Australia. Religious Education Journal of Australia, 29(1), 34-40.

Kosalina, N. (2018). Gambaran kesejahteraan subjektif lansia yang aktif dalam kegiatan religius. Jurnal Psibernetika, 11(1), 31-46. Diakses dari https://journal.ubm.ac.id/index.php/psibernetika/article/view/1158/1007

Krok, D. (2015). Religious coping and well-being in middle adulthood: The mediational role of meaning in life. https://doi.org/10.1007/s10943-014-9983-3.

Musa, A. S., Pevalin. D. J., \& Shahin, F. I. (2015). Impact of spiritual well-being, spiritual perspective and religiosity on the self-rated health of Jordanian Arab Christians. Journal of Transcultural Nursing, 27(6), 1-8. https://doi.org/10.1177/1043659615587590

Mutak, A. A. (2014). Reposisi hati: memahami panggilan dan dinamika spiritualitas hamba tuhan. Jurnal Theologi Aletheia, 16(6), 46-65. http://sttaletheia.ac.id/wpcontent/uploads/2014/04/reposisi-hati1.pdf.

Muzakkiyah, N., \& Suharnan. (2016). Religiusitas, penyesuaian diri dan subjektif well being. Persona Jurnal Psikologi Indonesia, 5(1), 28-38

Rishmawy, D. (2016). The church usher's vital priestlyrole. Christianity Today. Diakses pada Juli 8, 2020, dari https://www.christianitytoday.com/ct/2016/july-webonly/church-ushers-vital-priestly- role.html

Rohim, R. (2016). Hubungan antara spiritualitas dan manajemen stres pada individu paruh baya [Skripsi, Universitas Muhammadiyah].

Saleem, R., \& Khan, S. A. (2015). Impact of spirituality of well-being among old age people. The International Journal of Indian Psychology, 2(3), 172-181

Sandi, F. A. (2017). Motivasi menjadi pendamping pendidikan iman anak (PIA) ditinjau dari persepsi terhadap tugas pendampingan. [Thesis, Universitas Katolik Soegijapranata]. http://repository.unika.ac.id/15596/. Diakses pada 12 September 2019

Santrock, J. W. (2011). Life-span Development (13rd ed.). NY: McGraw-Hill

Sari, M. Y. (2016). Pelayan Perempuan di Gereja Bethel Indonesia Rayon IV Sumatera Resort, [Skripsi, Universitas Sumatera Utara].

Shafi, H., Bashir, N., \& Yousuf, U. (2016). Relationship between spiritual well-being, life satisfaction and depression: A study of middle aged people. The International Journal of Indian Psychology, 3(2), 147-154. http://oaji.net/articles/2016/1170-1454069748.pdf

Shirkavand, L., Abbaszadeh, A., Borhani, F., \& Momenyan, S. (2018). Correlation between spiritual well-being with satisfaction with life and death anxiety among elderlies suffering from cancer. Electronic Journal of General Medicine, 15(3), 1-7. doi: $10.29333 /$ ejgm/85501

Sodiq, A. (2016). Konsep kesejahteraan dalam Islam. Equilibrium: Jurnal Ekonomi Syariah, 3(2), 380-405. doi: http://dx.doi.org/10.21043/equilibrium.v3i2.1268

Sumiwi, A. R. E. (2019). Menerapkan konsep pelayan tuhan perjanjian baru pada masa kini. Jurnal Teologi dan Pelayanan Kristiani, 3(2), 94-106. http://dx.doi.org/10.33991/epigraphe.v3i2.129

Undang-undang Republik Indonesia Nomor 11 Tahun 2009 Tentang Kesejahteraan Sosial. Diakses dari https://luk.staff.ugm.ac.id/atur/sehat/UU-11-2009KesejahteraanSosial.pdf. Diakses pada 26 September 2019 
Wilkinson, J., Francis, L. J., \& McKenna, U. (2018). Personal prayer, worship attendance and spiritual wellbeing: a study among fourth, fifth and sixth class students attending church of Ireland schools in the republic of Ireland. Journal of Religious Education, 66, 203-212. https://doi.org/10.1007/s40839-018-0068-6

Yanaputri, A. Y. (2016). Studi diferensial mengenai spiritual well-being pada dewasa madya lakilaki dan perempuan di kota Bandung [Skripsi, Universitas Kristen Maranatha]. 